\title{
ULUSLARARASI İNSAN HAKLARI HUKUKUNDA ÜÇÜNCÜ DÜNYA YAKLAŞIMLARI
}

\author{
THIRD WAY APPROACHES TO INTERNATIONAL HUMAN RIGHTS LAW
}

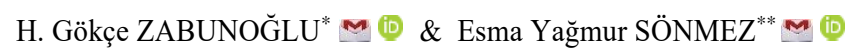

\begin{tabular}{l} 
Makale Bilgi \\
\hline Gönderi: 25/11/2020 \\
Kabul : 12/04/2021 \\
Anahtar Kelimeler \\
Üçüncü Dünya \\
Yaklaşımlarl, \\
Avrupa Merkezcilik, \\
Emperyalizm, \\
Imsan Haklarl.
\end{tabular}

\section{Article Info}

Received: $25 / 11 / 2020$ Accepted: 12/04/2021

\section{Keywords}

Third World Approaches to International Law, European Centrism, Imperialism, Human Rights.

\begin{abstract}
Özet
https://dai.org/l0.21492/inuhfd.831025 do

Uluslararası Hukukta Üçüncü Dünya Yaklaşımları (TWAIL), politik ve entelektüel bir hareket olarak eleştirel uluslararası hukuk literatüründe öne çıkmaktadır. Bu yaklaşıma göre Avrupa merkezli uluslararası hukuk kurallarının Avrupalı olmayan milletlere dikte edilmesi ile bu kurallar, Avrupalı devletlerin emperyalist ideallerini gerçekleştirmelerinin aracı haline gelmektedir. Uluslararası hukukun tarihini, yapısını ve sürecini Üçüncü Dünya devletleri açısından anlama çabasını temsil ettiği ileri sürülen TWAIL, çok sayıda perspektife sahip olan politik ve entelektüel bir hareket olarak dikkat çekmektedir. Sömürgeci ve egemen birinci dünya ile uluslararası hukukun mevcut yapısı arasındaki ilişkiye meydan okumak TWAIL'in belkemiğini oluşturmaktadır. TWAIL düşüncesine göre insan hakları tek bir kültürün ya da insanın ayrıcalığı değildir. Bu nedenle Avrupa merkezci yaklaşıma ciddi eleştiriler getirir. Evrensellik düşüncesine karşı çıkmayan TWAIL'in itirazı, bu evrenselliğin Avrupa merkezli olmasınadır Bu çalışmada, TWAIL'i tanımlayarak onun temel prensiplerini ortaya koymak amacı güdülmüş, uluslararası insan hakları hukuku TWAIL prensipleri dikkate alınarak yeniden kurgulanmaya çalışılmış, yaklaşımın insan haklarını ele alış, biçimi ile uluslararası insan hakları hukukun nasıl yeniden üretilebileceği incelenmiş ve birbiriyle ilişkili olan üç çözüm listelenmiştir. Bu çözümlerin insan hakları hukukunun kapsayıcıllğının arttırılması, iktidar mantığı ile hareket etmenin dışlanması ve insan hakları alanında tepeden inmeci yaklaşımların değiştirilmesi olduğu belirlenmiştir.
\end{abstract}

\begin{abstract}
Third World Approaches in International Law (TWAIL) stands out in the critical international legal literature as a political and intellectual movement. As a result of dictating European-based international law rules to non-European nations, these rules become a means for European states to realize their imperialist ideals. TWAIL, which is claimed to represent an effort to understand the history, structure and process of international law in terms of Third World states, draws attention as a political and intellectual movement with many perspectives.Challenging the relationship between the colonialist and the dominant first world and the existing structure of international law is the backbone of TWAIL. According to TWAIL's thought, human rights are not the privilege of a single culture or a person. Therefore, it brings serious criticism to the Eurocentric approach. The objection of TWAIL, which does not oppose the idea of universality, is that this universality is European-centered. In this study, it is aimed to reveal the basic principles by defining TWAIL and it was tried to reconstruct the international human rights law by considering TWAIL principles and the human rights assessment of this approach has been examined and how international human rights law can be reproduced accordingly and three related solutions are listed. These solutions have been identified as increasing the inclusiveness of human rights law, ceasing to act with the logic of power and abandoning topdown approaches in the field of human rights.
\end{abstract}




\section{GİRIŞ}

1980'lerde yaşanan gelişme ve değişmeler uluslararası ilişkiler disiplinindeki baskın pozitivist anlayışın sorgulanmaya başlaması sonucu doğururken, Soğuk Savaş'ın bitmesi ile bu eleştirel bakış açılarının disiplin içerisindeki yeri ve önemi giderek artmıştır. O zamana kadar hem uluslararası ilişkilere hem de teorik anlamda doğrudan etkilediği uluslararası hukuka mutlak hakim olan pozitivist anlayış, 1980'lerden sonra birçok farklı açıdan eleştirilmiş ve bu alternatif bakış açıları tarafindan yeni meta-teorik anlayışlar ortaya konulmaya başlamıştır.

$\mathrm{Bu}$ alternatif bakış açılarından biri olan uluslararası hukukun tarihini, yapısını ve sürecini Üçüncü Dünya ${ }^{1}$ devletleri açısından anlama çabasını temsil ettiği ileri sürülen ${ }^{2}$ Uluslararası Hukukta Üçüncü Dünya Yaklaşımları (Third Way Approaches to International Law-TWAIL), çok sayıda perspektife sahip olan politik ve entelektüel bir hareket ${ }^{3}$ olarak eleştirel uluslararası hukuk literatüründe öne çıkmaktadır. TWAIL kapsamında gerçekleştirilen ilk akademik konferans 1997 y1lına tekabül etmekteyse de bu yaklaşımın temel esasları uzun bir geçmişe sahip olan uluslararası enternasyonalizmin bir parçasıdır.

$\mathrm{Bu}$ çalışmada, küreselleşmenin az gelişmiş ülkeler ve bu ülkelerin insanları üzerinde yarattı̆̆ olumsuz sonuçlara bir tepki olarak ortaya çıkan ${ }^{4}$ uluslararası hukuktaki eleştirel bakış açılarından biri olan TWAIL'i tanımlamak ve bu yaklaşımın temel prensiplerini ortaya koymak amacı güdülmektedir. Bu amaca hizmet etmesi açısından ise, söz konusu yaklaşımın insan haklarını ele alış biçimi ile TWAIL bakış açısı kapsamında uluslararası insan hakları hukukun nasıl yeniden üretilebileceği örnek olay olarak incelenecektir.

Başka bir deyişle bu çalışmada uluslararası insan hakları hukuku, TWAIL prensipleri dikkate alınarak yeniden inşa edilmeye çalışılacaktır. Bu bağlamda üç temel kısımdan oluşan çalışmanın ilk bölümünde TWAIL yaklaşımının temelleri ortaya konulacak ve ayrıntılandırılmaya çalışılacaktır. İkinci bölümde ise, günümüzde geçerliliğini sürdüren uluslararası insan hakları hukukunun TWAIL tarafından nasıl eleştirildiği ifade edilecek ve son bölümde ise TWAIL ilkeleri dikkate alınarak yeni uluslararası insan hakları hukukunun anlayışı önerisi sunulacaktır.

\section{NEDİR?}

II. ULUSLARARASI HUKUKTA ÜÇÜNCÜ DÜNYA YAKLAŞIMLARI (TWAIL)

Önde gelen tarihçilerden biri olan Verzij tarafından da ifade edildiği gibi, uluslararası hukuk yalnızca Avrupa'nın bilinçli faaliyetinin bir ürünü değil, aynı zamanda hayatı özünü Batı Avrupa medeniyetinin inanç ve değer sistemlerinin oluşturduğu bir yapıdır ${ }^{5}$. Bir başka ifade ile uluslararası hukukun kuruluşu ve gelişiminin incelenmesi sonucunda görülecektir ki Avrupa merkezcilik bu hukukun hem temelini hem de ayrılmaz bir bütününü oluşturmaktadır. Bu gerçeğin bir sonucu olarak ise Avrupa dışındaki medeniyetlerin uluslararası hukukun oluşumunda ve gelişiminde dışlanması ortaya çıkmaktadır. Avrupa ürünü olan ve Avrupa sorunlarıyla ilgilenen bir dizi doktrin ve prensipten oluşan uluslararası hukuk, Angie'ye göre emperyalizm ve uluslararası hukuk ilişkisinin bir göstergesi olarak da okunabilir ${ }^{6}$. Bu yönüyle mevcut uluslararası hukuk sistemi, Avrupa'nın emperyalist amaçlarla Üçüncü Dünya'yı yağmalamasını ve kendi kontrolü altında tutmasını yasallaştıran bir sistemdir. Dolayısıyla medeniyetsiz ve geri kalmış Avrupalı olmayan insanları uluslararası hukuk bağlamında medenileştirme projesi emperyalizmin farklı bir yansımasıdır. Avrupa düşüncesinin temelinde bulunan ve Avrupalıyı kimseye benzemez yapmanın bir yolu olarak belirtilen ve kökeni ötekileştirmeye dayanan bir kimlik yaratımı mevcuttur. Bu yaratımın oluşumu ise Avrupa'nın

\footnotetext{
${ }^{1}$ Üçüncü Dünya kavramı, genel olarak ilk kez Alfred Sauvy'nin L'Observatuer gazetesinde 14 Ağustos 1952'de yayımlanan Üç Dünya, Bir Gezegen (Trois mondes, une plante) makalesinde kullanıldığı kabul edilir. Ancak kavramın kökeni hakkında tartı̧̧ma mevcuttur. Kimi yazarlara göre terimin ilk kez Charles de Gaulle tarafından kullanıldığı iddia edilmektedir. Ancak genel olarak halen terimin Sauvy'nin icadı olduğu kabul edilmektedir. Sauvy bu kelimeyi "tiers état" teriminden uyarlamıştır (SUNTER, Andrew F.:"Twail as naturalized epistemological inquiry", Canadian Journal of Law and Jurisprudence, 20(2), 2007, s.482).

${ }^{2}$ CHIMNI, Bhupinder S.: "The Past, Present and Future of International Law: A Critical Third World Approach" Melbourne Journal of International Law, (8), 2007, s.499.

${ }^{3}$ MUTUA, Makau/ANGHIE, Antony: "What is TWAIL?", Proceedings of the Annual Meeting, American Society of International Law, (94), 2000, s.36.

4 ÖZDEMIR, Ali M./UĞURLU, Göksu/AYKUT, Ebubekir: "Üçüncü Dünyacılık Küreselleşirken?: Uluslararas1 Düzenlemenin Değişen Eleştirisi,” Amme İdaresi Dergisi, 45(1), 2012, s.21.

${ }^{5}$ VERZIJ, Jan H. W.: International Law in Historical Perspective, Volume 1. Leiden, AW Sijthof, 1968, s.435-436.

${ }^{6}$ ANGHIE, Antony: "The Evolution of International Law: Colonial and Postcolonial Realities", Third World Quarterly, 27(5), s.740-741.
} 
diğerleriyle yaptığı savaşlardaki bozgunlardır?

$\mathrm{Bu}$ görüşü savunan Fitzpatrick ve Smith gibi yazarlar, uluslararası hukukun gelişmesiyle emperyalizmin yalnızca görünüş değiştirdiğini ancak özünü korumaya devam ettiğini savunmaktadırlar ${ }^{8}$. Avrupa merkezli uluslararası hukuk kurallarının Avrupalı olmayan milletlere hukuk adı altında kural olarak dikte edilmesi ile mevcut uluslararası hukuk kuralları, Avrupalı devletlerin emperyalist ideallerini gerçekleştirmelerinin bir aracı haline gelmektedir.

$\mathrm{Bu}$ şekilde sömürgeci ve egemen bir birinci dünya ile uluslararası hukukun mevcut yapısı arasındaki ilişkiye meydan okumak TWAIL'in bel kemiğini oluşturmaktadır. Böyle tanımlanan TWAIL her ne kadar bütüncül bir varlık oluşturmasa da tarihe duyarlı araştırma yöntemleri ve Avrupa medeniyetinden aşağıda görülen diğer medeniyetler anlayışına karşı çıkılması geniş, heterojen ve çok merkezli bir dağınık ağ olan TWAIL perspektifini birleştiren iki temel noktadır ${ }^{9}$. Buna ek olarak, eşitliksiz, adaletsiz ve haksız küresel düzeni açığa çıkarma, reform yapma ve hatta geri alma fikri, Üçüncü Dünya Yaklaşımcıları arasındaki bir diğer ortak paydadır ${ }^{10}$. Buna paralel olarak, uluslararası hukukun genel teorisinin yeniden gözden geçirilmesi; uluslararası düzenin işleyişinin sorgulanması; devlet teorisi ve anayasal düzen, güvenlik gibi kavramların gözden geçirilerek alternatifler üretilmesi; uluslararası insan hakları hukuku, ekonomi hukuku, çevre hukuku gibi farklı hukuk alanlarının çapraz incelemeye tabi tutulması gibi çalışmalar, TWAIL ile ilgilenen akademisyenlerin son yıllarda en çok gündeme aldığı konulardandır.

Tam da bu noktada, Üçüncü Dünya Yaklaşımlarının, üzerine çeşitli tartışmalar yaşanan, kökeninden kısaca bahsedilmesi yerinde olacaktır. Mutua tarafından temsil edilen bir görüşe göre, TWAIL yeni bir olgu değildir ve kökenleri II. Dünya Savaşı'ndan sonra dünyayı sarsan dekolonizasyon hareketine kadar uzanmaktadır. 1955 Bandung Konferansı ise, TWAIL'in sembolik doğum yeri olarak kabul edilmektedir. Bu nedenle, sömürgecilik sonrası dönem, dekolonizasyona bir cevap olarak ve Avrupalı olmayanlar üzerindeki Avrupa sömürgeci yönetiminin sona ermesi olan TWAIL'in başlangıcına işaret etmektedir ${ }^{11}$. Gathii tarafından temsil edilen bir başka bakış açısına göre ise, TWAIL'in kökenlerine ulaşmak için 1990'lara kadar gitmek ve özellikle yakın dönemdeki Kuzey Amerika'yı incelemek yeterlidir ${ }^{12}$. Özdemir ve diğerlerinin yorumuna göre ise TWAIL'in getirmiş olduğu yorum, 1950-1970 arasında etkin olan sosyalist, bağımsızlık yanlısı yazarların başarısızlıklarının 1şı̆̆ında ve var olan küreselleşme koşullarında özgün bir yeniden değerlendirilmesini içerir ${ }^{13}$.

Chimni tarafindan önerilen diğer bir görüş ise yukarıdaki iki farklı görüşten daha çok kabul görmektedir. Buna göre, TWAIL'in zaman içerisinde geçirmiş olduğu değişim ve gelişimi incelemek için süreci TWAIL I ve TWAIL II olarak ayırmak gereklidir ${ }^{14}$. TWAIL I olarak ifade edilen dönem 1950-1980 yılları arasını kapsarken; 1990'lardan günümüze kadar olarak süreç TWAIL II olarak adlandırılmaktadır. Bu iki dönemin Üçüncü Dünyacı düşüncesi arasında iddia ve varsayımlar yönünden ciddi farklılıklar bulunmaktadır ${ }^{15}$. Abi-Saab, Syatauw ve Weeramantry gibi düşünürler TWAIL I'i; Antony Anghie, Bhupinder S. Chimni, James Gathii, Karin Mickelson, Vasuki Nesiah, Obiora Okafor ve Balakrishnan Rajagopal gibi düşünürler ise TWAIL II'yi temsil eden en önemli isimlerdir ${ }^{16}$. Bu iki kuşak ayrımının yanı sıra kimi yazarlar 11 Eylül saldırıları sonrası küresel güvenlik ve terörizmle ilgili konuların uluslararası gündemdeki merkeziyetine dikkat çekerek bireylerden odağını tekrardan devletlere geri döndüren bir TWAIL III tanımlamasını öngörmüş̧ ${ }^{17}$ olmakla birlikte

\footnotetext{
${ }^{7}$ SAYGILI, Abdurrahman: İnsan Haklarının Evrenselliği Masalı: Bir Omfalos Olarak Avrupa. Ankara, İmaj, 2018, s.73-74.

${ }^{8}$ FITZPATRICK, Peter/DARIAN-SMITH, Eve: Laws of the Postcolonial, University of Michigan Press, 1999, s.4.

${ }^{9}$ GATHII, James T.: "TWAIL: A Brief History of its Origins, its Decentralized Network, and a Tentative Bibliography". Trade Law and Development, 3(1), 2011, s.34.

${ }^{10}$ OKAFOR, Obiora C.: "Newness, Imperialism, and International Legal Reform in Our Time: A TWAIL Perspective", Osgoode Hall Law Journal, 43(1-2), 2005, s.177.

${ }^{11}$ MUTUA, Makau/ANGHIE, Antony: "Proceedings of the Annual Meeting", American Society of International Law, 94, 2000, s.31

${ }^{12}$ GATHII, s.46.

${ }^{13}$ ÖZDEMIR/UĞURLU/AYKUT, s.23.

${ }^{14}$ ANGHIE, Antony/CHIMNI, Bhupinder S.: "Third World Approaches to International Law and Individual Responsibility in Internal Conflicts”. Chinese Journal of International Law, (2), 2003, s.79.

15 ÖZDEMIR/UĞURLU/AYKUT, s.23.

${ }^{16}$ CHIMNI, Bhupinder S.: International Law and World Order: A Critique of Contemporary Approaches, New York, Cambridge University Press, 2017, s.15.

${ }^{17}$ KHOSLA, Madhav: "The TWAIL Discourse: The Emergence of a New Phase", International Community Law Review, (9), 2007, s.291-304.
} 
bu yaklaşım TWAIL literatüründe çoğunluk tarafından kabul görmemiştir ${ }^{18}$.

Chimni ve Anghie tarafından yazılan ve TWAIL literatürünü derinden etkileyen makalede TWAIL I'in beş ayırt edici özelliği listelenmiştir. Bu listeye göre; uluslararası hukukun varlığı, Üçüncü Dünya halklarının Avrupa medeniyeti tarafından zapt edilmesini ve kendi çıarları doğrultusunda baskı altında tutulmasını meşrulaştırma amacına yöneliktir. Ayrıca Üçüncü Dünya devletleri Avrupalılar tarafından vurgulandığı gibi uluslararası hukuk fikrine hiç de yabancı değillerdir. TWAIL I'in bir başka ayırt edici özelliği ise; Birinci ve Üçüncü Dünyayı olduğu kadar Kuzey ve Güney’i birbirine bağlayan ekonomik yapıların Üçüncü Dünyanın ve Güney'in dezavantajlı konumunun devamında etkili olduğu ve yalnızca politik bağımsızlığın arzu edilen adil düzenin oluşumu için yeterli olmadığı fikridir. Bu nedenledir ki "Yeni bir Uluslararası Ekonomik Düzen" kurulması TWAIL I bakış açısı için kritiktir".

Bu noktada TWAIL'in kendi öncesinden ayıran iki husus olduğunu da belirtmek gereklidir. Bunlardan ilki TWAIL'in geliştiği yapının etkisidir ki bir dönem politik bir hareket içerisinde bulunan post-kolonyal ülkelerin, bugünün dünya sistemi içerisindeki konumlarını değerlendirme dış1 bırakmaktadırlar. İkincisi ise kapsayıcı bir teori ve pratik inşa etmedeki gönülsüzlüktür ${ }^{20}$.

Bununla birlikte, bu çalışmanın odak noktası, TWAIL I'in devlet merkezli yaklaşımını daha insan merkezli bakış açısıyla yeniden ele alan ve uluslararası hukuk ile sömürgecilik arasındaki problemli ilişkiyi ortaya çıkarmayı hedefleyen TWAIL II veya diğer bir adıyla çağdaş TWAIL olacaktır. Bu kapsamda Üçüncü Dünya üzerinde uluslararası hukuk kisvesi altında meşrulaştırılan, yeniden üretilen ve sürdürülen Batı hakimiyeti TWAIL'in temel eleştiri noktasıdır. Bu eleştiri; uluslararası hukuku bir baskı ve itaat rejimi olarak ele alan reaktif bakış açısı ile içsel bir dönüşüm, değişim, karşı koyma ve özgürleşme olarak ele alan proaktif yaklaşımın birleşimidir ${ }^{21}$.

$\mathrm{Bu}$ birleşimin bir sonucu olarak, birbiriyle ilişkili bir reaktif ve iki proaktif amaç TWAIL'in tanımlanması açısından önemlidir. Bunlardan ilki olan reaktif amaç kapsamında; TWAIL Avrupalı olmayanları Avrupalılara tabi kılan ırkçılaştırılmış uluslararası normlar ve kurumlar hiyerarşisini sorunsallaştırarak, uluslararası hukukun kullanım amaçlarını anlamayı, ortaya dökmeyi ve yeniden yapılandırmayı hedeflemektedir. Proaktif amaçlarından biri ise, mevcut hukuki düzene alternatif bir yapı inşa ederek, bu yeni düzeni uluslararası yönetişimin normatif bir yolu olarak sunmaktır. Yine bununla ilgili olarak TWAIL, Üçüncü Dünya'daki azgelişmişlik koşullarını burs ve politika yoluyla ortadan kaldırmayı amaçlamaktadır22.

TWAIL'i anlamak için altı çizilmesi gereken bir başka önemli nokta ise, Üçüncü Dünya olarak ifade edilen kavramdan ne anlaşılması gerektiğidir. TWAIL kapsamında ele alınan Üçüncü Dünya, Rajagopal'ın politik ve ekonomik organizasyon farklılıklarına dikkat çekerek Birinci ve İkinci Dünyadan ayırdığ 1 jeopolitik tanımdan uzaktır²3. Aksine, Üçüncü Dünya ile anlatılmak istenen, uluslararası sisteme karşı tarihsel olarak oluşturulmuş alternatif ve muhalif bir duruşu temsil eden heterojen yapıdır. Sonuç olarak, bütün tabloyu yansıtmasa da TWAIL perspektifinden anlaşılması gereken Üçüncü Dünya, güçlülere karşı zayıfların oluşturduğu bir uluslararası protesto olarak tanımlanabilecek bir sosyal harekettir ${ }^{24}$. Bu kritik reaktif yaklaşımla, TWAIL'in temel amacı, uluslararası hukukun mevcut formülasyonunun Üçüncü Dünya üzerinde nasıl bir etkisi olduğunu bulmaktır.

$\mathrm{Bu}$ nedenle, TWAIL, uluslararası hukuku ve kurumları analiz etmek için hem teorileri hem de metodolojileri sunan geniş, bir yaklaşım olarak tanımlanabilir. Başka bir deyişle, ilgili bir doğal veya sosyal varlık kümesinin davranışını tanımlamak için kullanılan ve mantıksal olarak kendi içerisinde tutarlı bir model olması yoluyla bir teori olan TWAIL, aynı zamanda bir faaliyette kullanılan bir yöntemler bütünü olarak da bir metodolojidir ${ }^{25}$. Dolayısıyla, TWAIL geleneksel bir yöntem değildir, ancak uluslararası hukukun ne olduğunu, nasıl olması ve bunu araştırmak için kullanılacak analitik araçların neler olması gerektiğine dair farklı düşünme yollarıdır.

\footnotetext{
${ }^{18}$ GALINDO, George R. B.: "Splitting TWAIL", Windsor Yearbook of Access to Justice, 33(3), 2016, s.43.

${ }^{19}$ ANGHIE/CHIMNI, s.80-82.

${ }^{20}$ ÖZDEMIR/UĞURLU/AYKUT, s.25-27.

${ }^{21}$ MUTUA/ANGHIE, Proceedings of the Annual Meeting, s.31.

${ }^{22}$ MUTUA/ANGHIE, Proceedings of the Annual Meeting, s.31.

${ }^{23}$ RAJAGOPAL, Balakrishnan: "Locating the Third World in Cultural Geography", Third World Legal Studies, 15(2), 1999, s.1.

${ }^{24}$ MICKELSON, Karin: "Rhetoric and Rage: Third World Voices in International Legal Discourse", Wisconsin International Law Journal, 16(2), 1998, s.357-360.

${ }^{25}$ OKAFOR, Obiora C.: "Critical Third World Approaches to International Law (TWAIL): Theory, Methodology, or Both?", International Community Law Review, (10), 2008, s.376-378.
} 
Yukarıda TWAIL'e dair ortaya konulan bütün bilgiler bir araya getirildiğinde, TWAIL perspektifinden anlaşılması gereken; Üçüncü Dünya'nın tahakkümüne, baskılanmasına ve dezavantajlı durumuna ortam hazırlayan ve sürdürülmesinde rol oynayan uluslararası hukuk rejiminin eşitliksiz, haksız ve adil olmayan karakterine karşı geniş, çaplı eytişimdir ${ }^{26}$. TWAIL'in eleştirel yaklaşımlar içindeki özgünlüğü, alternatif bilgi eksikliğinin var olduğu Batı merkezli ana akım hukuk söylemine karşı cesur müdahalelerinden gelir. Böylece uluslararası hukuktaki Batı merkezciliği yıkmak teorik alternatifler geliştirilmesini desteklemesi ve epistemik farkl1lıkları alternatif dünyaların inşası için zemin olarak alması TWAIL'e orijinallik kazandırır. Buna ek olarak, akademisyenleri ve aktivistleri mevcut düzene tahakküm etmek yerine farklı bir uluslararası hukuk düzeni hayal etmeye ve bu hayalin inşası için çalışmaya çağırması, TWAIL'i diğer eleştirel bakış açılarından ayıran kritik bir yeniliktir ${ }^{27}$.

\section{ULUSLARARASI İNSAN HAKLARI HUKUKUNA GETIRILEN ELEŞTIRILLER}

Chimni, modern uluslararası hukuktaki çelişkilerin belki de en iyi şekilde uluslararası insan hakları hukuku alanında ortaya çıktığını savunmaktadır. Bu görüş özellikle mülkiyet hakkının uluslararasılaştırılmasının meşrulaştııılması ile yoksul ve marjinal grupların dezavantajlı durumunu artıracak şekilde sivil, siyasi, sosyal, kültürel ve ekonomik haklarının hegemonik müdahalelere uğraması gerçeğine dayanmaktadır ${ }^{28}$. Kinsella tarafından iddia edildiği gibi, uluslararası insan hakları hukukunu uluslararası hukukun bireysel kollarını güçlendirmek için bir araç, olarak görürsek ${ }^{29}$, özellikle Üçüncü Dünya'daki insan hakları ihlallerine karşı koruyucu bir güç, işlevi görmesi beklenebilir. Öte yandan, TWAIL uluslararası insan hakları hukukunun Üçüncü Dünya'nın Batı tarafından bastırılmasına, yoksullaştııılmasına ve haklarının elinden alınmasına yardım eden bir emperyalizm aracı olarak hareket ettiğini ortaya koymaktadır. Bu yönüyle TWAIL, uluslararası insan hakları hukukuna ilişkin ana akım söylemi birçok yönüyle sorunlu bulmaktadır. Bu bağlamda, uluslararası insan hakları hukukunda baskın olan Avrupa merkezcilik ve ırk, din, medenileşme seviyesi gibi kriterlere bağlı olarak yapılan dışlamalar TWAIL tarafından bu hukuk dalının mevcut haline getirilen eleştirilerin temelini oluşturmaktadır ${ }^{30}$.

Söz konusu dışlamalar özelinde bakıldığında, uluslararası insan hakları hukukunun yalnızca Avrupalı insanların haklarını korur şekilde uygulanarak Avrupa dışındaki insanların konu olduğu çatışmalara, bir başka deyişle sömürge savaşlarına uygulanmaması ya da Avrupa'nın çıkarları nispetinde ve onların işine gelecek şekilde uygulanması dikkat çekicidir. Bir başka dışlama şekli de uluslararası insan hakları hukukunun Avrupalı olmayan milletlerin katkıları gözetilmeden yaratılması ve uygulanmasidir ${ }^{31}$.

Bu nedenle, uluslararası insan hakları hukukunun TWAIL perspektifinden anlaşı1ması, ana akım söylemin yapısal sorunlarının tanınması ve düzeltilmesi için esastır. Bu nedenle, hem normatif hem de politik hedefleri olan TWAIL temsilcileri, uluslararası hukukla ilgili önemli konuları sorgulamanın ve alanlarının tarihsel evrimine odaklanmanın yanı sıra insan hakları eleştirisine de yoğunlaştılar ${ }^{32}$. TWAIL'e göre, uluslararası insan hakları hukukunun Üçüncü Dünya'nın ihtiyaçlarına cevap verebilmesinin tek yolu, radikal bir gözden geçirme ve yeniden yapılanma ile Avrupa insan hakları topluluğunun evrenselleştirilmesi çabalarının terk edilmesidir. TWAIL'in genel anlamda uluslararası hukuka ve özelde uluslararası insan hakları hukukuna dair çok çeşitli ve heterojen bir yaklaşım olduğu unutulmadan, bu görüşün insan hakları hukukuna ilişkin eleştirileri genel kategoriler halinde aşağıda listelenmeye çalışlacaktır.

\section{A. Uluslararası İnsan Hakları Hukukunda Avrupa Merkezlilik}

Uluslararası insan haklarının temeli açıkça Avrupa merkezlidir. II. Dünya Savaşı sonrası zihniyetin bir ürünü olarak, İnsan Hakları Evrensel Beyannamesi (Universal Declaration of Human Rights- UDHR) ve onun iki uygulayıcı anlaşması olan Uluslararası Medeni ve Siyasi Haklar

\footnotetext{
${ }^{26}$ OKAFOR: Newness, Imperialism, and International Legal Reform in Our Time, s.176.

${ }^{27}$ ESCOBAR, Arturo: Territories of Difference: Place, Movements, Life, Redes, Duke and London, Duke University Press, 2008, s.310-311.

${ }^{28}$ CHIMNI, Bhupinder S.: "Third World Approaches to International Law: A Manifesto", International Community Law Review , (8), 2006, s.26.

${ }^{29}$ KINSELLA, Helen M.: The Image Before the Weapon: A Critical History of the Distinction, New York, Cornell University Press, 2011, s.13

${ }^{30}$ FORSTER, Thomas: "International Humanitarian Law's Old Questions and New Perspectives: On What Law Has Got to Do With Armed Conflict", International Review of the Red Cross, 98(3), 2016, s.1009.

${ }^{31}$ BADARU, Opeoluwa A.: "Examining the Utility of Third World Approaches to International Law for International Human Rights Law”, International Community Law Review, (10), 2008, s.380.

32 BACHAND, Remi: Critical Approaches and the Third World. Towards a Global and Radical Critique of International Law. Speech at University McGill 24.3.2010.
} 
Sözleşmesi (International Covenant on Civil and Political Rights-ICCPR) ve Uluslararası Ekonomik, Sosyal ve Kültürel Haklar Sözleşmesi (International Covenant on Economic, Social and Cultural Rights-ICESCR), Birinci Dünya egemenliğinin uluslararası hukuktaki doğrudan sonuçlarıdır. Bunlara ek olarak, Kadınlara Karşı Her Türlü Ayrımcılığın Önlenmesi Sözleşmesi (Convention on the Elimination of All Forms of Discrimination against Women-CEDAW), İşkence ve Diğer Zalimane, İnsanlık Dışı ya da Aşağılayıcı Muamele ve Cezanın Önlenmesi Sözleşmesi (Convention against Torture and Other Cruel, Inhuman or Degrading Treatment or Punishment- CAT) gibi aşağıdaki temel uluslararası insan hakları araçları da aynı Batı baskınlığı altında oluşturulmuştur ${ }^{33}$.

Evrensel Bildiriye değin, insan haklarının gelişimi, Batı sınırları içerisinde kalmıştır. Batı kültürü içerisinde gelişen ve olgunlaşan insan hakları düşüncesinin evrensel olup olamayacağ 1 Bildirinin hazırlık sürecinde de ABD'nin başını çektiği liberal kapitalist Batı ve Sovyetlerin öncülüğündeki sosyalist blokları arasında tartışılmıştır ${ }^{34}$. İnsan Hakları Evrensel Beyannamesi'nin uluslararası bir anlaşma değil de bir Birleşmiş Milletler Genel Kurul Kararı olması ve oluşturulma zamanlaması gibi belgenin temel karakterini oluşturan hususlar, bu belgenin ne denli Avrupa-merkezci olduğunun en önemli göstergeleridir. Bu iki gösterge bir arada incelendiğinde, söz konusu belgenin adında geçen evrensel kelimesinin aksine, yalnızca 1948 yılında Birleşmiş, Milletler Genel Kurulu'nda bulunma ayrıcalığına sahip olan sınırlı sayıda üyenin eseri olduğu açıktır. Yine bu gerçekten yola çıkarak iddia edilebilir ki: O yıllarda Üçüncü Dünya üzerindeki sömürgeciliğini sürdüren emperyalist Birinci Dünya devletleri, İnsan Hakları Evrensel Beyannamesinin tek ve asıl yaratıcısıdır. Bu nedenle, Batı devletlerinin sömürge işgalinde olan Üçüncü Dünya halkının, bu beyannamenin şekillenmesinde hiçbir rolü olamamıştır.

İşte bu nedenledir ki Mutua, uluslararası insan hakları rejiminin çok büyük bir kısmının Batı'da birkaç yüzyıl boyunca gelişen iç hukuk organlarından kaynaklandığını savunmaktadır ${ }^{35}$. Başka bir deyişle, İnsan Hakları Evrensel Beyannamesi ve sonraki uygulama anlaşmaları, Batı normlarının bir tür yansımasıdır. Benzer şekilde, Cassese, Avrupa Devletlerinin 1948'de Birleşmiş Milletler Genel Kurulundaki baskın rolünün, onlara kendi insan hakları felsefelerini Dünya'nın geri kalanına ve özellikle de Üçüncü Dünya'ya dayatma imkânı sağladığını iddia etmektediri ${ }^{36}$. Dolayısıyla bu açık Batı orijini, uluslararası insan hakları hukukunun özgüllüğü ve Üçüncü Dünya'nın dışlanması noktalarında TWAIL eleştirilerine yol açmaktadır. Ancak bu eleştiri ile şu hususu özellikle belirtmek gerekir. TWAIL'e göre uluslararası hukuku ortaya çıkaran normlar ve değerler Avrupalıdır ancak bu evrensellik düşüncesine bir karşı duruş olarak okunmamalıdır. Evrensellik kaçınılmaz olan bir şeydir ve bu TWAIL düşüncesinde de olumlanmaktadır. İtiraz bu evrenselliğin Avrupa merkezli olmasınadır. Dolayısıyla savlanan evrenselliğin Avrupa merkeziyetçiliğinden çıkarılmasıdır ${ }^{37}$.

\section{B. Uluslararası İnsan Hakları Hukukunda Özgülllük}

Uluslararası insan hakları hukukundaki Avrupa merkezciliğinin doğrudan bir sonucu, Avrupalıların evrensellik iddiasının aksine bu alanda var olan özgüllüktür. İnsan Hakları Evrensel Beyannamesinin önsözünde belirtilen "İnsanlık topluluğunun bütün fertleriyle uzuvlarının bu beyannameyi daima göz önünde tutarak (...) bu hakların dünyaca fiilen tanınmasını ve tatbik edilmesini sağlamaya gayret etmeleri amacıyla bütün halklar ve milletler için ulaşılacak ortak ideal olarak işbu İnsan Hakları Evrensel Beyannamesi'ni ilan eder" ifadesi bile bu alandaki evrenselliğe ne denli büyük anlam yüklendiğini ortaya koyar niteliktedir.

Batı liberal demokrasilerinde kabul edilen medeni ve siyasi hakların evrenselleştirilme çabası olarak da okunabilen bu durum, aynı zamanda Batı'nı Üçüncü Dünya üzerindeki siyasi ve ekonomik ideallerinin saf bir yansımasıdır ${ }^{38}$. Bu demokrasilerdeki dünyayı medenileştirme idealine paralel olarak, evrensel olduğu iddia edilen uluslararası insan hakları hukuku Üçüncü Dünya üzerinde bir baskı aracı olarak kullanılmaktadır. Başka bir deyişle, İnsan Hakları Evrensel Beyannamesinde yer alan hakların "tüm insanlar", "herkes", "hiç kimse" gibi kelimelerle formüle edilmesi, bu hakların alt metinlerinde yer alan Batı normları ve ideallerinin tek doğru yol olarak kabul edilmesi ve normatif

\footnotetext{
${ }^{33}$ NURMAYANI, Dewi: What are Human Rights? (7 Mart 2013),

https://www.globalethicsnetwork.org/profiles/blogs/what-are-human-rights, (Erişim Tarihi: 15 Mart 2020)

${ }^{34}$ ZABUNOĞLU, H. Gökçe: "Kültürel Görecelik ve İnsan Haklarının Evrenselliği’, Zabunoğlu Armağanı, Ankara, Ankara Üniversitesi Yayınları, 2011, s.798.

${ }^{35}$ MUTUA, Makau: “The Ideology of Human Rights”, Virginia Journal of International Law, (36), 1996, s.604.

${ }^{36}$ CASSESE, Antonio: "The General Assembly Historical Perspective: 1945-1989”, in Altson P. (ed), The United Nations and Human Rights: A Critical Appraisal, New York, Oxford University Press, 1992, s.31-32.

${ }^{37}$ ÖZDEMIR/UĞURLU/AYKUT, s.45.

${ }^{38}$ MUTUA, The Ideology of Human Rights, s.606.
} 
gerçeklik olarak uygulanması hedefine yöneliktir.

Bu standardizasyonun Batılı kökenleri bir yandan Üçüncü Dünya ülkelerinin ihtiyaçlarına hitap etmekten uzak bir insan hakları hukuku oluşmasına neden olurken, bir yandan da Üçüncü Dünyanın insan hakları konusunda Batılı ülkeler tarafından eğitilmeye muhtaç, olduğu algısını yaratmaktadır ${ }^{39}$. Bu nedenle, Higgins gibi liberal bazı yazarlara göre, Üçüncü Dünya ülkeleri Avrupalılar tarafindan insan hakları konusunda acil olarak eğitilme ihtiyacındadır. Yine bu bakış açısıyla, İnsan Hakları Evrensel Beyannamesi; insan haklarının tam olarak güvence altına alındığına inanılan Batı devletlerinin liberal demokrasileri için değil, Üçüncü Dünya ülkeleri için gereklidir ${ }^{40}$. Benzer şekilde, Henkin, uluslararası insan hakları hukukunu evrensel olarak tasvir etmenin temelinde yatan sebebin Amerika Birleşik Devletleri ve benzer özelliklere sahip az sayıdaki liberal devlet dışındaki ülkelerde insan haklarının mevcut durumunu geliştirmek için olduğunu iddia etmektedir ${ }^{41}$.

$\mathrm{Bu}$ tartışmaya önemli katkılarda bulunan isimlerden biri olan Okafor, uluslararası insan hakları hukukunu "Cennet/Cehennem İkilemi" (The Heaven/Hell Binary) kavramsallaştırması yoluyla eleştirmektedir ${ }^{42}$. Bu kavramsallaştırmaya göre, insan hakları yönünden Batı kendini cennet olarak nitelerken, Üçüncü Dünya'yı tam karşısına cehennem olarak koymaktadır. Dolayısıyla uluslararası insan hakları hukukunun yapısı, bu problemli Cennet-Cehennem İkileminin yeniden üretilmesine katkıda bulunmaktadır. Bu yeniden üretimin ana yollarından biri, Batı dünyasındaki insan hakları ihlallerinin dikkatli bir şekilde örtülmesinin aksine, Üçüncü Dünya'daki insan hakları ihlallerinin yoğun bir şekilde gündeme taşınmasıdır. Bu kayıtsızlık aslında Batı'nın her açıdan olduğu gibi insan haklarında da yeterince iyi ve cömert olduğu fikrinin altını çizmektedir.

Bu tür bir kavramsallaştırma, Mutua'nın mevcut insan hakları hukukunu nasıl "barbar-kurbankurtarıcı" (savage-victims-saviors) üçgeni bağlamında eleştirdiğini de hatırlatır niteliktedir ${ }^{43} . \mathrm{Bu}$ üçgene göre, Üçüncü Dünya ülkeleri uluslararası insan hakları hukuku açısından barbardırlar ve kendi halklarını kurban etmektedirler. Bu nedenle, buralarda yaşanan insan hakları ihlallerine bir dur diyebilmek için bir kurtarıcıya ihtiyaç vardır ki bu kurtarıcı da Batılı devletler ile onların norm ve kurallarıdır. Mutua, bu anlayışı sorunsallaştırarak Avrupa'nın üstünlüğü önyargısı ve bu üstünlüğü sağlayan paradigmalar olarak Hıristiyanlık, ticaret ekonomisi ve politik emperyalizmin uluslararası insan hakları hukukunun temelini oluşturduğunu savunmaktadır. Dolayısıyla, uluslararası insan hakları, Batı'nın Avrupa merkezli normları ve kültürel formları evrenselleştirme girişiminin bir parçası olarak, sömürge devletinin yaratılması ve belirli ekonomik, sosyal ve politik modellerin baskınlığını kurmanın bir başka yoludur ${ }^{44}$.

\section{C. Üçüncü Dünyanın Uluslararası İnsan Hakları Hukuku İnşasından Dışlanması}

Mevcut uluslararası insan hakları hukukunun dışlayıcı niteliği göz önüne alındığında, TWAIL, insan haklarının hukuki söylemini Üçüncü Dünya deneyimini de içerecek şekilde yeniden düzenleme ihtiyacına işaret etmektedir. TWAIL perspektifine göre insan hakları normlarının inşası ve tanımı dinamik ve sürekli süreçlerdir. Dolayısıyla, insan hakları tek bir kültürün ya da insanın ayrıcalığı değildir. $\mathrm{Bu}$ anlamda, gerçekten evrensel bir insan hakları anlayışı oluşturmak tüm kültürlerin madenciliği gerekmektedir ${ }^{45}$.

Donnelly'ın söylediğinin aksine insan hakları Afrikalı, Kızılderili, geleneksel İslami sosyal sistemler gibi farklı toplumlara hiç de yabancı değildir. Bu toplumlarda da ve aslında her toplumda insanlık onurunu, ahlaki ve etik standartlarını korumayı amaçlayan normlar yer almaktadır. Tek fark, farklı toplumlarda farklı mekanizmalar işletilmesidir ${ }^{46}$.

$\mathrm{Bu}$ nedenle, insan hakları söyleminin gelişmesi için, Batılı olmayan milletlerin de katkılarının dikkate alınması gerekmektedir. Ancak uluslararası hukukun oluşumu ve gelişimi açısından bakıldığında sömürgeciliğin zirveye ulaştığı on dokuzuncu yüzyıldan bugüne değin Avrupa devletleri

\footnotetext{
${ }^{39}$ BADARU, s.381.

40 HIGGINS, Rosalyn: "Ten Years on the UN Human Rights. Committee: Some Thoughts", European Human Rights Law Review, (6), 1996, s.571-582.

${ }^{41}$ HENKIN, Louis: The Age of Rights. New York, Columbia University Press, 1990, s.74.

42 OKAFOR, Obiora C.: "International Human Rights Fact-finding Praxis in its Living Forms: A TWAIL Perspective", The Transnational Human Rights Review, (1), 2014, s.67.

${ }^{43}$ MUTUA, Makau: "Savages, Victims, and Saviors: The Metaphor of Human Rights", Harward International Law Journal, 42(1), 2001, s.201.

${ }^{44}$ MUTUA, Savages, Victims, and Saviors, s.214.

${ }^{45}$ MUTUA, Makau: "The Banjul Charter: The Case for an African Cultural Fingerprint", Cultural Transformation and Human Rights in Africa. London/New York, Zed Books, 2002, s.71-72.

${ }^{46}$ MUTUA, Makau: "The Banjul Charter and the African Cultural Fingerprint: An Evaluation of the Language of Duties", Virginia Journal Of International Law, 35, 1995, s.345-346; MUTUA, Savages, Victims, and Saviors, s.207.
} 
egemen ve kendi aralarında eşit iken egemen olmayan ya da en azından kısmen egemen olduğu kabul edilen Avrupalı olmayan toplumlarla Avrupa devletleri arasında eşit olmayan bir ilişki süregelmektedir ${ }^{47}$. Okafor, bu konuyu vurgulayarak, uluslararası insan hakları hukukunda "Tek Yönlü Trafik Paradigmasını" (The One-Way Traffic Paradigm) eleştirmektedir ${ }^{48}$. Okafor, bu argümanını daha önce ifade edilen "Cennet / Cehennem İkilemi" argümanı ile birleştirerek, uluslararası insan hakları hukukundaki ana akım anlayışı sorunsallaştırmaktadır. $\mathrm{Bu}$ nedenle, insan hakları fikir ve uygulamalarının münhasıran insan hakları cenneti olarak kabul edilen Batıdan insan hakları cehennemi olarak kabul edilen Üçüncü Dünyaya akışını ve dikte edilmesini eleştirmektedir ${ }^{49}$. Bir başka deyişle, ana akım uluslararası insan hakları hukuku; Batılı olmayanların Batı tarafından sürgün edilmesine, Üçüncü Dünyanın cehennem, barbar ve insan haklarından bihaber şekilde resmedilmesine ve insan haklarının emperyalist idealleri gerçekleştirmek için bir araç olarak kullanılmasına ortam sağlamaktadır.

Batı'nın Üçüncü Dünya'ya karşı insan haklarında benimsemiş, olduğu öğreticiliğinin göstergelerinden biri, Batı'da merkezlenen ve Üçüncü Dünya'da aktif olan Sivil Toplum Örgütlerinin sayısıdır. Smith, Pagnucco ve Lopez'in yaptığı araştırmaya göre, çoğu uluslararası insan hakları Sivil Toplum Örgütü Batı Avrupa'da ve Kuzey Amerika'da konuşlanmakla birlikte aktif olarak Üçüncü Dünya'da insan hakları aktivisti olarak çalışmaktadır ${ }^{50}$. Aynı şekilde, Mutua da Batı merkezli Sivil Toplum Örgütlerinin faaliyetlerinin çoğunun Üçüncü Dünya'da odaklandığı bir resim sunmaktadır. Öte yandan, bu yoğun olarak Üçüncü Dünya'da odaklanan insan hakları çalışmaları, Üçüncü Dünyanın vahşi olduğu ve kültürel, politik ve ekonomik açıdan üstün Batı'nın oradaki kurbanların tek kurtarıcısı olduğu önyargılı analojisini ortaya koymaktadır ${ }^{51}$.

Tam da bu noktada TWAIL düşüncesi, Üçüncü Dünyanın insan hakları konusunda yalnızca Batının çalışma alanı olarak ele alınmasının gerçekçi olmadığını ve bir bilgi kaynăğ olarak Üçüncü Dünya'nın katkısı olmadan çokkültürlü ve bütünleştirici insan hakları söyleminin geliştirilmesinin mümkün olmadığını savunmaktadır. Avrupa merkeziyetçi yaklaşımların iddia ettiği özgür insan öznenin, bireysel hakların savunusunun müteakip örneklerde görüldüğ̈ gibi Avrupalı olmayanlar tarafından da gerçekleştirilebilecektir. Örneğin Elias, Afrika hukukundaki -her ne kadar sosyal sözleşme hakkında yerel teoriler formüle edilmemiş olmakla birlikte neredeyse tüm Afrika toplumlarında görülen mitsel kuruluşunun isimsiz bir ata tarafından gerçekleştirildiğini anlatan kurucu ata mitiyle belirginleşen- egemenlik ve hükümet anlayışının Grotius tarafından ortaya konan -toplumun ve egemenin kökenine ilişkin varsayımsal sözleşmeci inşa anlayışı ve bu varsayım temelinde insanların hükümdara itaatinin mutlak bir görev olduğunun gerekçesi olarak gösterdiği "pacta sund sevanda sunt" maksiminden oluşan- anlayıştan çok da farklı olmadığı gerçeğinin altını çizmektedir ${ }^{52}$. Bir başka örnek olarak, çoğunlukla Gana ve Fildişi Sahili bölgesinde yaşayan Akan halkı içinde insanlık onurunun değeri her bireyin kendine özgü olduğu kabul edilir. Ayrıca, herkesin Tanrı'ın çocuğu olarak görülmesi nedeniyle, yaşama hakkına saygı gösterilmesi gerektiği ve hiçbir kimsenin yargılama olmadan cezalandırılmaması gerektiği temel kurallardandır ${ }^{53}$.

Buna ek olarak, insanın sadece insan olduğu için değer görmesi gerektiği fikrinin yaygın olduğu Doğu Afrika'daki Akamba toplumunda, toplumun tüm üyelerinin eşit olarak doğdukları ve cinsiyet, yaş gibi kriterlerden bağımsız olarak eşit muamele görmeleri gerektiği toplumsal bir kabuldür. Benzer şekilde, Güney Sudan topraklarında yaşayan Dinka'da insan onuruna saygı, geleneksel olarak insan ilişkilerini yönlendiren ve düzenleyen ahlaki kuralların ve toplumsal düzenin toplamını oluşturan davranış, ilkelerinin ayrılmaz bir parçası olmuştur ${ }^{54}$.

Sonuç olarak, tüm bu örnekler Üçüncü Dünya'nın uluslararası insan hakları söylemini geliştirmek için büyük bir potansiyele sahip olduğunun açık göstergeleridir. Ayrıca, bu potansiyel,

\footnotetext{
${ }^{47}$ ANGHIE, Antony: Imperialism, Sovereignty and the Making of International Law, Cambridge: Cambridge University Pres, 2004, s.5.

${ }^{48}$ OKAFOR, International Human Rights, s.72.

${ }^{49}$ OKAFOR, Obiora C./AGBAKWA, Shedrack C.: "Re-Imagining International Human Rights Education in Our Time: Beyond Three Constitutive Orthodoxies", Leiden Journal of International Law, 14(3), 2001, s.575.

${ }^{50}$ SMITH, Jackie/PAGNUCCO, Ron/LOPEZ, George A.: "Globalizing Human Rights: The Work of Transnational Human Rights NGOs in the 1990s", Human Rights Quarterly, 20(2), 1998, s.386.

${ }^{51}$ MUTUA, Savages, Victims, and Saviors, s.216.

${ }^{52}$ ELIAS, Taslim O.: Africa and Development of International Law, Dordrecht, Martinus Nijhoff, 1988, s.36.

${ }^{53}$ LENZERINI, Federico: "The African System for the Protection of Human and People's Rights: Pan-Africanism, Solidarity and Rights", in Maluwa Tiyanjana (ed), Law, Politics and Rights: Essays in Memory of Kader Asmal, Leiden, Martinus Nijhoff Publishers, 2014, s.22.

${ }^{54}$ LENZERINI, s.22.
} 
emperyalist Batılı devletlerin medenileşme olarak adlandırdıkları misyonun bir sonucu da değildir. $\mathrm{Bu}$ devletlerin kültürel normlarına ve değerlerine özgüdür. Bu nedenle, Avrupalı ve Avrupalı olmayan devletlerin arasındaki ilişki, uluslararası insan hakları hukuku ana söyleminde iddia edildiği gibi hiyerarşik değildir. Bu nedenle, insan hakları fikirlerinin Batı'dan dünyanın geri kalanına tek yönlü olarak dikte edilmesini engellemek ve Üçüncü Dünyanın da değerli katkılarıyla çok kültürlü ve dünyanın her tarafının dengeli bir şekilde temsil edildiği yeni bir insan hakları hukuku oluşturmaya acil ihtiyaç vardır.

\section{TWAIL İLKELERINE GÖRE İNSAN HAKLARI HUKUKU ÖNERİSI}

TWAIL'in ne olduğunu ve mevcut insan hakları yasasını nasıl eleştirdiğini vurguladıktan sonra, TWAIL eleştirileri doğrultusunda insan hakları hukukunun alternatif bir formunun nasıl oluş̧urulacağı bu bölümde sunulacaktır. Bu alternatif form aşağıda listelendiği üzere üç temel sacayağı üzerinde yükselecektir.

\section{A. Daha Kapsayıcı bir İnsan Hakları Hukuku Yaratılması}

İnsan hakları hukukunun evrensellik ve kapsayıc1lık iddiaları büyük ölçüde retorikten ve temenniden öteye gidememektedir. Bu durumun temel nedeni ise insan hakları fikrinin tarihsel olarak kapsayıc1lıktan yoksun olması ve Avrupa merkezli temelleridir ${ }^{55}$. İnsan hakları hukukunun her insan için adil bir dünya düzeni sağlamaya yönelik olduğu göz önüne alındığında, bu hukukun özellikle Üçüncü Dünya ideallerinden yararlanarak Avrupa merkezcilikten kurtulması ve daha kapsayıcı bir karakter kazanması olmazsa olmazdır. Uluslararası insan hakları hukukunda bu kapsayıcı niteliğe ulaşmak için, şu ana kadar baskın olan Batı monoloğu, Üçüncü Dünya ile Batı arasında eşit ortaklar olarak gerçek bir diyalogla değiştirilmelidir.

Bu diyaloğun gelişmesinin önündeki en önemli engel ise, kapsayıcı bir insan hakları hukukunun milliyetçilik akımlarını tetikleyerek sömürgecilik dâhil tüm siyasi tahakküm biçimlerine yeni saldırı zeminleri sağlayacağı endişesidir ${ }^{56}$. Bu endişeden hareketle insan hakları hukukunda ortaya çıkan Batı'dan Üçüncü Dünya'ya tek yönlü fikir akışının kırılarak çok yönlü bir paylaşım yöntemi geliştirilmesi kapsayıcı bir insan hakları hukuku için vazgeçilmezdir. Söz konusu yöntem geliştirilirken, insan haklarının yasal evrenselliğinin yaptırımlardan ziyade gittikçe çeşitlenen insani durumlarla ilgili standart ve kavramların ne kadarını kapsadığına bağlı olduğu ${ }^{57}$ akılda tutulmalıdır. Buna bağlı olarak da, Okafor'un “Tek Yönlü Trafik Paradigması” olarak adlandırdığı, ırk, etnik köken, yaş, din, cinsel yönelim veya cinsiyet nedeniyle bazı grupların bu hakların kullanımında sistematik olarak dezavantajlı olduğu mevcut düzen yerine, özellikle mülteci ve kadın haklarının özel sözleşmelerde düzenlenmek yerine, temel metne dahil edildiği bir sistem yaratılmalıdır.

Mülteci hakları açısından bakıldığında, Mülteci Sözleşmesi kapsamındaki hakların uygulanmasının izlenmesi ve aksi takdirde yaptırım uygulanması yetkisine sahip bir antlaşma organı mekanizmasının oluşturulması vazgeçilmezdir ${ }^{58}$. Kadına Karşı Her Türlü Ayrımcıllğıı Ortadan Kaldırılması Sözleşmesi'nin onaylanmasına diğer insan hakları antlaşmalarından daha fazla devletin çekince koyduğu ${ }^{59}$ gerçeğinden hareketle, Batı emperyalizminin korunmasına hizmet eden bu anlayış yerine, kadın haklarının insan haklarının temel bir unsuru olduğunun ve kadına yönelik şiddetin kültürel bir unsur olarak kabul edilmesinin mümkün olmadığının temel metne eklenmesi gereklidir ${ }^{60}$.

Bu bağlamda, yalnızca Batı'nın değil, Üçüncü Dünya'nın seslerinin de duyulduğu ve Üçüncü Dünya'nın marjinalleşmesinin ortadan kaldırıldığı bir düzen öngörülmektedir. İnsan haklarının daha kapsayıcı niteliği ile Batı ve Üçüncü Dünyayı birbirlerinden öğrenecek bir şeyleri olan eşit diyalog

\footnotetext{
${ }^{55}$ IBHAWOH, Bonny: "Inclusion versus Exclusion”, in Mihr Anja/Gibney Mark (ed), The SAGE Handbook of Human Rights: Two Volume Set. London, SAGE Publications., 2014, s.324-325.

${ }^{56}$ SIMPSON, Alfred W. Brian: Human Rights and the End of Empire: Britain and the Genesis of the European Convention. New York, Oxford University Press, 2001, s.455.

${ }^{57}$ DUQUETTE, David: "Universalism and Relativism in Human Rights", in Reidy David A./Sellers Mortimer N.S. (ed), Universal Human Rights: Moral Order in a Divided World. Oxford, Rowman \& Littlefield, 2005, s.59: BREMS, Eva: Human Rights: Universality and Diversity, Leiden, Martinus Nijhoff Publishers, 2001, s.21.

${ }^{58}$ BEYANI, Chaloka: "The Role of Human Rights Bodies in Protecting Refugees", Anne F. Bayefsky (der.), Human Rights and Refugees, Internally Displaced Persons and Migrant Workers. Leiden, Brill., 2006, s.281.

59 ARAT, Zehra F.: "Promoting Women's Rights agains Patriarchal Cultural Claims: The Women's Convention and Reservations by Muslim States", in Forsyhte David/McMahon Patrice (der), Human Rights and Diversity: Area Studies Revisited, Lincoln:University of Nebraska Pres, s.233

${ }^{60}$ ROSS, Susan D.: Women's Human Rights: The International and Comparative Law Casebook, Philadelphia, University of Pennsylvania Press, 2008, s.xxix; MERRY Sally E., Human Rights and Gender Violence: Translating International Law into Local Justice, Chicago, University of Chicago Press, 2006, s.292.
} 
partileri olarak kabul edilecek ve sömürgeciliğin insan hakları hukuku yoluyla yeniden üretilmesinin de önüne geçilmiş olacaktır.

\section{B. İnsan Hakları Hukukunda Ulusal Çıkarların Bir Kenara Bırakılması}

Yukarıda ifade edilen şekliyle Batı monoloğu yerine Batı ile Üçüncü Dünya arasında oluşturulacak olan diyalog ulusal çıkarlara dayanmamalıdır. Başka bir deyişle, mevcut uluslararası insan hakları hukukunu geliştirmek için kurulacak olan çok boyutlu iş birliği, iktidar mantığı ile değil, insan haklarında evrenselliğin genişlemesine katkıda bulunmak için yapılmalıdır. Bu evrenselliğin yaratılmasının önündeki en büyük engel ise, küreselleşme döneminde, ulusal çıkarları savunduğunu iddia eden üçüncü dünyadaki yönetici seçkinler ile ulus ötesi sermayeyi elinde tutan Batılı yönetici elitler arasında kurulan ve Üçüncü Dünya halklarının insan haklarını dışlayan işbirliğidir. Üçüncü Dünya yönetici elitlerinin kendi çıkarlarına ve emperyalizmin yeniden yaratılmasına hizmet eden bu işbirliği içerisinde ulusal çıkar kavramı Üçüncü Dünya'nın tahakkümünde bir meşrulaştırma aracına dönüşmektedir ${ }^{61}$. Bu anlamda, Üçüncü Dünyadaki yönetici elitlerinin ulus ötesi işbirliklerini yok etmeden, çok boyutlu ve kapsayıcı bir insan hakları hukuku yaratmak mümkün değildir. Ayrıca, uluslararası hukukun yapıldığı ve uygulandığı mevcut biçimin özellikle Batı'ın büyük güçlerinin ulusal çıkarlarını yansıtması uluslararası insan hakları hukukundaki Batı monoloğunun yeniden üretilmesine neden olmaktadır ${ }^{62}$.

Ulusal çıkarların öncelikli kılınmasının ve ortak çıkarların önünde tutulmasının, sömürgeciliği insan hakları hukukuna verdiği zararları tekrar edeceği akılda tutarak, insan hakları hukuku devletler tarafından elit kesimin ulusal çıkar olarak benimsettiği çıkarların değil tüm insanlığın ve içeriğini halkın belirlemesi halinde elbette ulusal çıkarlarına hizmet etmenin bir aracı olarak görülmelidir. Bu anlamda, oluşturulacak yeni insan hakları düzeninde dünya arenasında tüm aktörlerin hak ve menfaatlerinin tamamen korunması önceliklidir ${ }^{63}$. Ancak bu şekilde uluslararası insan hakları hukuku, özgüllükten kurtulabilir ve gerçek bir evrensellik kazanabilir. Daha genel bir perspektiften bakıldığında, iktidar mantığı, insan haklarının ihlal edilmesine yol açan ana etken olduğundan, yeni insan hakları biçimi iktidar ilişkilerinden korunmalıdır. Bu korumaya giden yolda ortak çıkarları ve değerlerin devletlerin iç meselelerine derinlemesine nüfuz ettiği bir sistem yaratılması vazgeçilmez bir gerekliliktir ${ }^{64}$.

\section{C. İnsan Hakları Hukukunda Tepeden İnmeci Anlayışı Kırmak}

Bu alandaki tepeden inmeci yaklaşım, Avrupa merkezli yaklaşım ve seçkincilik olmak üzere iki farklı bakış açısından anlaşılabilir. Birinci anlayışa göre, Batı'nın insan haklarında Üçüncü Dünya'dan daha üstün olduğu iddiası, her yönüyle olduğu gibi, burada da sorunun ana kaynağıdır. Üçüncü Dünya' daki cehaletin ve yardıma muhtaç durumun aksine Batı'nın gerekli tüm bilgi ve deneyime sahip insan hakları öğretmeni olduğu benzetmesi bu anlamda yeniden gözden geçirilmelidir ${ }^{65}$. Başka bir deyişle, insan haklarında daha kapsayıcı bir yapı oluşturmanın tamamlayıcısı olarak, Okafor'un "Cennet/Cehennem İkilemi" metaforunda ifade ettiği durumun yeni insan hakları hukuku anlayışı ile farklı bir resmi sunulmalıdır. Benzer şekilde, Okafor da insan haklarını Batı-Üçüncü Dünya (veya Kuzey-Güney) ayrışmasının üstünde algılamanın, tüm insanlık için daha faydalı insan hakları fikirleri oluşmasına neden olacağını savunmaktadır ${ }^{66}$. Sonuç olarak, gerçekten evrensel bir uluslararası insan hakları ancak çok kültürlü ve hem Batı'nın hem de Üçüncü Dünya'nın karşılıklı katkılarıyla güvence altına alınabilir ${ }^{67}$.

Tepeden inmeci yaklaşımın ikinci görünüş biçimi olan seçkinciliğe göre, uluslararası insan hakları hukukunu devletlerin tekelinden çıkararak bir sosyal hareket düzeyine indirmek gereklidir ${ }^{68}$. Bu nedenle, TWAIL odaklı yeni insan hakları hukuku versiyonuna göre hem Batıda hem de Üçüncü Dünyada sivil toplumun bu hukukun oluşumuna katkısı derinleştirilmeli ve genişletilmelidir. Bu

\footnotetext{
${ }^{61}$ CHIMNI,"Third World Approaches to International Law: A Manifesto", s.7,18.

${ }^{62}$ FIDLER, David P.: "Revolt Against or From Within the West?: TWAIL, the Developing World, and the Future Direction of International Law". Articles by Maurer Faculty Paper 2126, 2003, s.38.

${ }^{63}$ ADEDE, Andronico O.: The Minimum Standards in a World of Disparities, in Macdonald Ronald ve Johnston Douglas M. (ed), The Structure and Process of International Law, Springer, 1983, s.1021.

${ }^{64}$ FIDLER, s.62.

${ }^{65}$ NADER, Laura: “A User Theory of Law”, Southwestern Law Jo., Say1 38, 1984, s.951; B. Tamanaha, A General Jurisprudence of Law and Society. Oxford, Oxford University Press, 2001, s.239-240.

${ }^{66}$ OKAFOR/AGBAKWA: Re-Imagining International Human Rights, s.575.

${ }^{67}$ RAJAGOPAL, Brian: International Law from Below: Developing Social Movements and Third World Resistance. Cambridge, Cambridge University Press, 2003.

${ }^{68}$ GLENN, H. Patrick: Legal Traditions of the World: Sustainable Diversity in Law, 2. Bask1, Oxford, Oxford University Press, 2004.
} 
noktada, özellikle Üçüncü Dünya kökenli sosyal hareketlerinin sürece dahil edilmesine özen gösterilmeli ve Batı kökenli Sivil Toplum Kuruluşlarının Üçüncü Dünya'daki aktivizmi sınırlandırılmalıdır. Üçüncü Dünya kökenli bu kuruluşların yeni insan hakları hukuku oluşum sürecine doğrudan ve aktif katılımları, insan hakları hukukunun küresel kapsayıcılığını ve evrenselliğini artırarak, TWAIL perspektifinden geliştirilen önceki iki çözümün verimliliğine katkıda bulunacaktır ${ }^{69}$. Ayrıca, Sivil Toplum Kuruluşlarını ve uzmanları sistemden dışladığı ve devlet egemenliğini tekel aldığından, sözleşme temelli insan hakları hukuku sistemi değiştirilmelidir.

\section{V.SONUÇ}

Bu çalışmada benimsenen vizyona göre, ağırlıklı olarak Batı kökenli olan ve bunun sonucunda evrensellik yerine özgüllük; kapsayıc1lık yerine dışlayıcılık temellerinde yükselen mevcut uluslararası insan hakları hukukundaki sorunlar, TWAIL eleştirilerini pragmatik çözümlere dönüştürerek çözülebilir. Başka bir deyişle, insan hakları hukukunda eksikliklerin giderilmesi için beklenen çözüm TWAIL'de bulunabilir. Ancak TWAIL'in de cevap vermediği hususlar mevcuttur. Evrenselliği kaçınılmaz olarak kabul eden ve bunun Avrupa merkezlilikten koparılması gerektiğini savlayan TWAIL'e göre mülkiyet hakkına dokunulmaksızın insanların ortak değeri korunabilecektir. Fakat her ne kadar mülkiyet, serbest piyasa gibi değerlerin insani değerlere üstün tutulamayacağ 1 ön kabulüne sahip olsa da bunların çatışması halinde hangi ilkelere göre bu çatışan değerlerden hangisinin korunacağı konusunu belirsiz bırakmaktadırlar. Hakeza TWAIL kapsamındaki önerilerin üçüncü dünya için neden iyi olduğu sorusuna da tam bir yanıt veremedikleri görülmektedir. Buna karşılık insan hakları hukukundaki eksiklikler bağlamında TWAIL eleştirilerinin incelendiği mevcut çalışmada birbiriyle ilişkili üç çözüm listelenmiştir. Buna göre, insan hakları hukukunun kapsayıcılığı arttırılmalı, iktidar mantığı süreçten dışlanmalı ve bu alandaki tepeden inmeci yaklaşımlar değiştirilmelidir. $\mathrm{Bu}$ üçünün aynı anda uygulanmasıyla, uluslararası insan hakları hukuku, TWAIL tarafindan önerildiği gibi çok kültürlü, evrensel ve kapsayıcı bir karakter kazanacaktır.

\section{KAYNAKÇA}

ADEDE, Andronico O.: The Minimum Standards in a World of Disparities, in Macdonald Ronald ve Johnston Douglas M. (ed), The Structure and Process of International Law, Springer, 1983.

ANGHIE, Antony: "The Evolution of International Law: Colonial and Postcolonial Realities", Third World Quarterly, 27(5).

ANGHIE, Antony: Imperialism, Sovereignty and the Making of International Law, Cambridge: Cambridge University Pres, 2004.

ANGHIE, Antony/CHIMNI, Bhupinder S.: "Third World Approaches to International Law and Individual Responsibility in Internal Conflicts". Chinese Journal of International Law, (2), 2003.

ARAT, Zehra F.: "Promoting Women's Rights agains Patriarchal Cultural Claims: The Women's Convention and Reservations by Muslim States", in Forsyhte David / McMahon Patrice (der), Human Rights and Diversity: Area Studies Revisited, Lincoln:University of Nebraska Pres., 2003.

BACHAND, Remi: Critical Approaches and the Third World. Towards a Global and Radical Critique of International Law. Speech at University McGill 24.3.2010.

BADARU, Opeoluwa A.: "Examining the Utility of Third World Approaches to International Law for International Human Rights Law", International Community Law Review, (10), 2008.

BEYANI, Chaloka: "The Role of Human Rights Bodies in Protecting Refugees", Anne F. Bayefsky (der.), Human Rights and Refugees, Internally Displaced Persons and Migrant Workers. Leiden, Brill., 2006.

BREMS, Eva: Human Rights: Universality and Diversity, Leiden, Martinus Nijhoff Publishers, 2001.

CASSESE, Antonio: “The General Assembly Historical Perspective: 1945-1989”, in Altson P. (ed), The United Nations and Human Rights: A Critical Appraisal, New York, Oxford University Press, 1992.

CHIMNI, Bhupinder S.: International Law and World Order: A Critique of Contemporary Approaches, New York, Cambridge University Press, 2017.

CHIMNI, Bhupinder S.: "The Past, Present and Future of International Law: A Critical Third World Approach" Melbourne Journal of International Law, (8), 2007.

CHIMNI, Bhupinder S.: “Third World Approaches to International Law: A Manifesto", International Community Law Review , (8), 2006.

${ }^{69}$ MACCORMICK, Neil: Institutions of Law: An Essay in Legal Theory. Oxford, Oxford University Press, 2007, s.288. 
DUQUETTE, David: “Universalism and Relativism in Human Rights”, in Reidy David A./Sellers Mortimer N.S. (ed), Universal Human Rights: Moral Order in a Divided World, Oxford, Rowman \& Littlefield, 2005.

ELIAS, Taslim O.: Africa and Development of International Law, Dordrecht, Martinus Nijhoff, 1988.

ESCOBAR, Arturo: Territories of Difference: Place, Movements, Life, Redes, Duke and London, Duke University Press, 2008.

FIDLER, David P.: "Revolt Against or From Within the West?: TWAIL, the Developing World, and the Future Direction of International Law", Articles by Maurer Faculty Paper 2126, 2003.

FITZPATRICK, Peter/DARIAN-SMITH, Eve: Laws of the Postcolonial, Ann Arbor, University of Michigan Press, 1999.

FORSTER, Thomas: "International Humanitarian Law's Old Questions and New Perspectives: On What Law Has Got to Do With Armed Conflict", International Review of the Red Cross, 98(3), 2016.

GALINDO, George R. B.: "Splitting TWAIL", Windsor Yearbook of Access to Justice, 33(3), 2016.

GATHII, James T.: "TWAIL: A Brief History of its Origins, its Decentralized Network, and a Tentative Bibliography". Trade Law and Development, 3(1), 2011.

GLENN, H. Patrick: Legal Traditions of the World: Sustainable Diversity in Law, 2. Bask1, Oxford, Oxford University Press, 2004.

HENKIN, Louis: The Age of Rights. New York, Columbia University Press, 1990.

HIGGINS, Rosalyn: "Ten Years on the UN Human Rights. Committee: Some Thoughts", European Human Rights Law Review, (6), 1996.

IBHAWOH, Bonny: "Inclusion versus Exclusion”, in Mihr Anja/Gibney Mark (ed), The SAGE Handbook of Human Rights: Two Volume Set. London, SAGE Publications., 2014.

KHOSLA, Madhav: "The TWAIL Discourse: The Emergence of a New Phase", International Community Law Review, (9), 2007.

KINSELLA, Helen M.: The Image Before the Weapon: A Critical History of the Distinction, New York, Cornell University Press, 2011.

LENZERINI, Federico: "The African System for the Protection of Human and People's Rights: Pan-Africanism, Solidarity and Rights", in Maluwa Tiyanjana (ed), Law, Politics and Rights: Essays in Memory of Kader Asmal, Leiden, Martinus Nijhoff Publishers, 2014.

MACCORMICK, Neil: Institutions of Law: An Essay in Legal Theory, Oxford, Oxford University Press, 2007. MICKELSON, Karin: "Rhetoric and Rage: Third World Voices in International Legal Discourse", Wisconsin International Law Journal, 16(2), 1998.

MUTUA, Makau: "Savages, Victims, and Saviors: The Metaphor of Human Rights", Harward International Law Journal, 42(1), 2001.

MUTUA, Makau: "The Banjul Charter and the African Cultural Fingerprint: An Evaluation of the Language of Duties", Virginia Journal Of International Law, 35, 1995.

MUTUA, Makau: “The Banjul Charter: The Case for an African Cultural Fingerprint”, Cultural Transformation and Human Rights in Africa. London/New York, Zed Books, 2002.

MUTUA, Makau: “The Ideology of Human Rights”, Virginia Journal of International Law, (36), 1996.

MUTUA, Makau/ANGHIE, Antony: "Proceedings of the Annual Meeting", American Society of International Law, 94, 2000.

MUTUA, Makau/ANGHIE, Antony: "What is TWAIL?", Proceedings of the Annual Meeting, American Society of International Law, (94), 2000.

NADER, Laura: “A User Theory of Law”, Southwestern Law Jo., Say1 38, 1984, s. 951; B. Tamanaha, A General Jurisprudence of Law and Society. Oxford, Oxford University Press, 2001.

NURMAYANI, Dewi: What are Human Rights? (7 Mart 2013), https://www.globalethicsnetwork.org/profiles/blogs/what-are-human-rights, (Erişim Tarihi: 15 Mart 2020)

OKAFOR, Obiora C.: "Critical Third World Approaches to International Law (TWAIL): Theory, Methodology, or Both?”, International Community Law Review, (10), 2008.

OKAFOR, Obiora C.: "International Human Rights Fact-finding Praxis in its Living Forms: A TWAIL Perspective", The Transnational Human Rights Review, (1), 2014.

OKAFOR, Obiora C.: "Newness, Imperialism, and International Legal Reform in Our Time: A TWAIL Perspective", Osgoode Hall Law Journal, 43(1-2), 2005.

OKAFOR, Obiora C./AGBAKWA, Shedrack C.: "Re-Imagining International Human Rights Education in Our Time: Beyond Three Constitutive Orthodoxies", Leiden Journal of International Law, 14(3), 2001.

ÖZDEMİR, Ali M./UĞURLU, Göksu/AYKUT, Ebubekir: "Üçüncü Dünyacılık Küreselleşirken?: Uluslararası Düzenlemenin Değişen Eleştirisi,” Amme İdaresi Dergisi, 45(1), 2012.

RAJAGOPAL, Balakrishnan: "Locating the Third World in Cultural Geography", Third World Legal Studies, 15(2), 1999.

RAJAGOPAL, Brian: International Law from Below: Developing Social Movements and Third World Resistance. Cambridge, Cambridge University Press, 2003. 
ROSS, Susan D.: Women's Human Rights: The International and Comparative Law Casebook, Philadelphia, University of Pennsylvania Press, 2008, s.xxix; MERRY Sally E., Human Rights and Gender Violence: Translating International Law into Local Justice, Chicago, University of Chicago Press, 2006.

SAYGILI, Abdurrahman: İnsan Haklarının Evrenselliği Masalı: Bir Omfalos Olarak Avrupa, İmaj, 2018.

SIMPSON, Alfred W. Brian: Human Rights and the End of Empire: Britain and the Genesis of the European Convention, New York, Oxford University Press, 2001.

SMITH, Jackie/PAGNUCCO, Ron/LOPEZ, George A.: "Globalizing Human Rights: The Work of Transnational Human Rights NGOs in the 1990s”, Human Rights Quarterly, 20(2), 1998.

SUNTER, Andrew F.: "Twail as naturalized epistemological inquiry", Canadian Journal of Law and Jurisprudence, 20(2), 2007.

VERZIJ, Jan H. W.: International Law in Historical Perspective, Volume 1. Leiden, AW Sijthof, 1968.

ZABUNOĞLU, H. Gökçe: “Kültürel Görecelik ve İnsan Haklarının Evrenselliği”, Zabunoğlu Armağanı, Ankara, Ankara Üniversitesi Yayınları, 2011. 